\title{
The geographical distribution of lymphatic filariasis infection in Malawi
}

\author{
Bagrey MM Ngwira*1,2, Phillimon Tambala3 ${ }^{3}$ A Maria Perez², \\ Cameron Bowie ${ }^{2}$ and David H Molyneux ${ }^{1}$
}

\author{
Address: ${ }^{1}$ Lymphatic Filariasis Support Centre, Liverpool School of Tropical Medicine, Pembroke Place, L3 5QA, UK, ${ }^{2}$ Malawi College of Medicine, \\ P/Bag 360, Blantyre3, Malawi and ${ }^{3}$ Onchocerciasis Control Programme, PO Box 2273, Blantyre, Malawi \\ Email: Bagrey MM Ngwira* - bngwira@africa-online.net; Phillimon Tambala - ief@malawi.net; A Maria Perez - sgraham@mlw.medcol.mw; \\ Cameron Bowie - cbowie@medcol.mw; David H Molyneux - david.molyneux@liv.ac.uk \\ * Corresponding author
}

Published: 29 November 2007

Filaria Journal 2007, 6:12 doi:10.1186/1475-2883-6-12

This article is available from: http://www.filariajournal.com/content/6/I//2

(c) 2007 Ngwira et al; licensee BioMed Central Ltd.

This is an Open Access article distributed under the terms of the Creative Commons Attribution License (http://creativecommons.org/licenses/by/2.0), which permits unrestricted use, distribution, and reproduction in any medium, provided the original work is properly cited.
Received: 17 April 2007

Accepted: 29 November 2007

\begin{abstract}
Mapping distribution of lymphatic filariasis (LF) is a prerequisite for planning national elimination programmes. Results from a nation wide mapping survey for lymphatic filariasis (LF) in Malawi are presented. Thirty-five villages were sampled from 23 districts excluding three districts (Karonga, Chikwawa and Nsanje) that had already been mapped and Likoma, an Island, where access was not possible in the time frame of the survey. Antigenaemia prevalence [based on immunochromatographic card tests (ICT)] ranged from $0 \%$ to $35.9 \%$. Villages from the western side of the country and distant from the lake tended to be of lower prevalence. The exception was a village in Mchinji district on the Malawi-Zambia border where a prevalence of $18.2 \%$ was found. In contrast villages from lake shore districts [Salima, Mangochi, Balaka and Ntcheu (Bwanje valley)] and Phalombe had prevalences of over $20 \%$.

A national map is developed which incorporates data from surveys in Karonga, Chikwawa and Nsanje districts, carried out in 2000 . There is a marked decline in prevalence with increasing altitude. Further analysis revealed a strong negative correlation $\left(R^{2}=0.7 p<0.00 \mathrm{I}\right)$ between altitude and prevalence. These results suggest that the lake shore, Phalombe plain and the lower Shire valley will be priority areas for the Malawi LF elimination programme. Implications of these findings as regards implementing a national LF elimination programme in Malawi are discussed.
\end{abstract}

\section{Background}

Lymphatic filariasis (LF) has been identified as a major public health problem and is endemic in over 80 countries. It is currently estimated that up to 120 million people are infected with Wuchereria bancrofti in about 83 endemic countries [1]. Of these, it is estimated 40 million people have evidence of chronic manifestations such as hydrocele and lymphoedema/elephantiasis. In addition the affected individuals suffer repeated episodes of ade- nolymphangitis ('acute attacks') which result in marked loss in their economic productivity [2]. Improved therapies and diagnostic methods have led to the realisation that it should be possible to interrupt transmission and eliminate LF by repeated, annual cycles of mass drug administration (MDA), with single dose combination regimens [3]. Thus, in 1997 the World Health Assembly passed a resolution calling for strengthening of activities leading to the elimination of LF as a "public health prob- 
lem [4]." This resulted in the initiation of the now wellestablished Global Program to Eliminate Lymphatic Filariasis (GPELF) in 2000.

Malawi has two previously known LF foci: one in the southern part (Shire valley) and the other in the northern region along the Songwe river which forms its border with Tanzania $[5,6]$. However there had been no detailed community based surveys for LF in Malawi apart from one in the northern focus which was conducted in 1960. This survey, based on microscopic examination (for microfilarae) of thick bloodsmears which were made from samples collected at night, showed a high prevalence of microfilaraemia amongst adults (40\%) and suggested that human infection with $W$. bancrofti was confined to communities in close proximity to the Songwe River [7].

More recently, surveys in these two foci have reported high antigenaemia prevalence based on immunochromatographic (ICT) card tests that approached $80 \%$ in some of the sampled villages $[8,9]$. There was also a higher than expected prevalence of LF associated disease in both areas ( $4 \%$ lymphoedema and up to $18 \%$ hydrocele). In addition, the survey in Karonga established that W. bancrofti infection is more wide spread than previously recognised, whereas in the lower Shire valley a markedly higher antigenaemia prevalence (55\%) was found amongst children (aged 1-9 years) than what has been reported in any of the published literature.

Towards the end of 2003 we completed a nation-wide mapping exercise using ICT cards. The objective was to obtain data on the geographical distribution of LF in the remaining districts in Malawi as a prerequisite to initiating national LF elimination activities. This paper presents findings from a 2003 survey and incorporates data from recent surveys in the two known foci that have already appeared in the scientific literature to produce, for the first time, a complete map of the distribution of LF infection (based on adult worm antigenaemia) in Malawi. The implications of this distribution for LF control programme planning and eventual implementation are discussed.

\section{Methods}

Malawi is administratively divided into northern, central and southern regions. These are further divided into 28 districts. Two new districts (Neno - parent district Mwanza and Likoma Island - parent district - NkhataBay) were formed after this survey had already been planned and thus were mapped within there parent districts. In addition, access to Likoma, an Island District, was not possible in the time frame of this survey. LF prevalence data were available for three districts; Karonga District in the northern region, Chikwawa and Nsanje
Districts in the southern region. The latest survey did not cover these districts. In the remaining districts we aimed to sample a random selection of villages for antigen testing. A database of villages by district was made available via the WHO's HealthMapper software. A programme incorporated in the software was used to provide a random sample of villages to be surveyed. The selected villages had a $50 \mathrm{~km}$ buffer zone as recommended by the WHO's rapid assessment for the geographical distribution of lymphatic filariasis (RAGFIL) method [10]. Three additional villages were chosen in the field from inhabited areas from where the database did not contain any villages. The testing protocol adopted followed recommendations of the RAGFIL method that is based on Lot Quality Sampling (LQAS) scheme [11]. Briefly, if at least $10(20 \%)$ of the first 50 individuals (aged $>15$ years) tested were positive testing could be stopped; otherwise up to 100 individuals were to be tested per sampling point [11]. However since many villages are sparsely populated an adjacent village to the randomly selected one were also invited to participate in order to achieve the required sample size. Hence random selection of subjects was not feasible in most villages. Before testing could be carried out a meeting with village members was held and the objectives of the survey were explained in the local language. Each consenting individual provided demographic data (age and sex) and a finger prick blood sample. The whole blood obtained was immediately applied onto the ICT (Binax Inc., Portland, ME) card and read within ten minutes according to the manufacturer's instructions. If two lines appeared in the viewing window that particular individual was regarded as positive for LF [12]. Individuals found positive were treated on the spot with albendazole (400 mg) and ivermectin (200 $\mu \mathrm{g} / \mathrm{kg}$ body weight). All sampled villages had geo-coordinates determined by a portable Geographical Positioning System (GPS-Garmin eTrex $^{\circledR}$ ) machine.

\section{Ethics}

The survey received ethical clearance from the Malawi Ministry of Health Sciences Research Committee (HSRC) and from the Liverpool School of Tropical Medicine Ethics Committee. Individual consent was obtained from each participant or (if they were aged $<16$ ) from one of their parents or a guardian.

\section{Data Management}

Data were entered into the computer using EPINFO 2000 (CDC, Atlanta) software. The data were subsequently exported into STATA version 7 (Stata Corporation, College Station, TX) for descriptive statistical analyses. In order to investigate the relationship between prevalence and altitude, log transformation of the prevalence data was carried out using the formula $\log _{10}(x+1)$. Village geographical coordinate data were used to produce a map 
showing the spatial distribution of LF infection using the WHO's HealthMapper software.

\section{Results}

A total of 35 data points were sampled. Of these three were chosen in the field in inhabited areas where there were no villages on the Healthmapper database. A total of 2913 individuals were examined. The age and sex distribution of the survey participants is shown in Figure 1. There was a female excess (64\%) amongst the study participants (more marked in the 20-24 age bracket). Overall there were 269 (9.2\%) individuals positive for circulating filarial antigen (CFA) based on ICT results. Significantly more males than females tested positive $(11.0 \%$ vs $8.2 \%$ $\mathrm{p}=0.01$ ). Figure 2 shows the proportion of those positive for CFA by age and sex. Amongst the males, those positive, tended to be older (student $t$ test $\mathrm{p}=0.08$ ). This relationship was not observed in their female counterparts.

Survey prevalence data by district and village are presented in Table 1 . This ranged from $0 \%$ to $35.9 \%$. The spatial distribution of the sampled villages with their prevalence category are shown in Figure 3. In general villages in the western side of the country registered a CFA prevalence of less than $10 \%$. This is with the exception of Mzenga Village in Mchinji District along the Malawi-Zambia border where a prevalence of $18.2 \%$ was found. Prevalence of over 20\% was observed from villages in Salima and Mangochi Districts along the southern shore of Lake Malawi. Also in Ntcheu district (Bwanje Valley), Balaka district near Lake Malombe and finally in Phalombe district along the shores of Lake Chilwa. The highest prevalence $(35.9 \%)$ was recorded at Kalembo village in Balaka district in southern Malawi.

Prevalence data from the 2000 surveys are summarised in Table 2. The geographical distribution of data points sam-

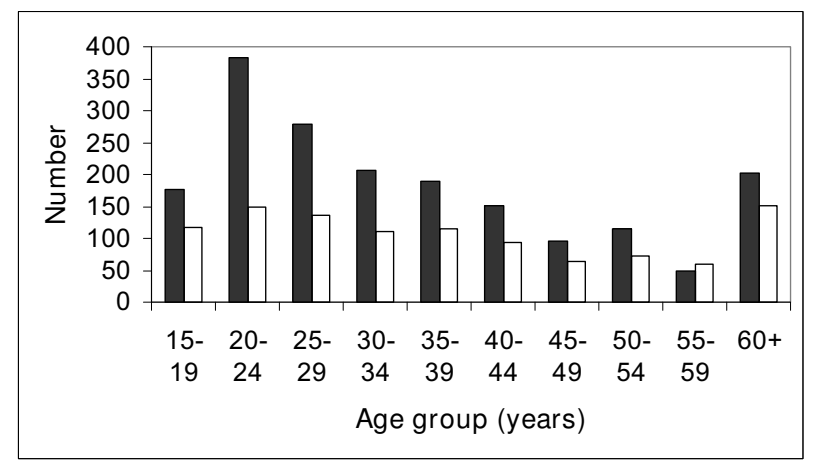

Female (ם); Male ( $\square$ )

\section{Figure I}

The age and sex distribution of survey participants.

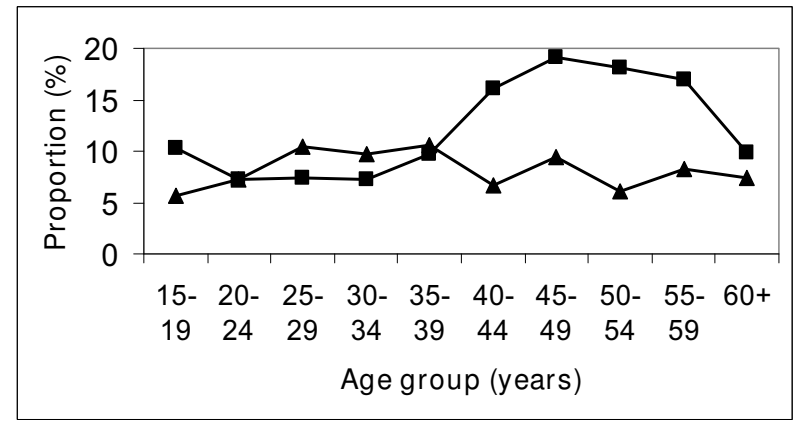

Females ( $\mathbf{\Delta})$; Males $(\boldsymbol{\square})$

Figure 2

The proportion of males and females positive for CFA by age.

pled (ICT) in Malawi (except two villages in Nsanje District where it was not possible to obtain geographical coordinates) showing prevalence in relation to altitude is presented in Figure 4. Figure 5(a) shows a scatter plot of antigen prevalence by altitude. There is notable decline in prevalence with increasing altitude and further statistical analyses on log transformed prevalence data [Figure 5(b)] have shown a significant negative correlation between altitude and prevalence $\left(\mathrm{R}^{2}=0.7 \mathrm{p}<0.001\right)$.

\section{Discussion}

The present survey, in the remaining unmapped districts in Malawi, has shown that infection with W. bancrofti as determined by antigenaemia prevalence is more widespread than previously appreciated. The female excess observed amongst our survey population probably reflects the fact that males are often out in the field during the day thus not available for testing. The implication of this being that the prevalence we found in some of our sampled villages is likely to be an under-estimate of the true prevalence. This is due to the fact that in most communities significantly more males tend to carry the infection as has been observed in this survey and in other surveys from Malawi and elsewhere in Africa $[9,13]$.

In all districts, except Chitipa in the north, there was at least one individual who was positive on ICT. The low prevalence found in villages from the western side of Malawi could be explained by the fact that these areas are dry, of relatively higher altitude and thus not ideal for extensive mosquito breeding. The $18.2 \%$ prevalence observed at Mzenga Village in Mchinji along the Zambia border is intriguing. This is particularly so as there have been no anecdotal reports of LF disease from either the Malawi or Zambia side of the border in this area. Of note is that this village is in close proximity to a perennial stream that sustains a reasonable amount of irrigated 
Table I: ICT antigen prevalence data from the nation wide survey conducted in 2003

\begin{tabular}{|c|c|c|c|c|c|c|}
\hline District & Village & Number tested & Number positive & Prevalence & Latitude & Longitude \\
\hline Balaka & Kalembo & 53 & 19 & 35.8 & 14.84500 & 35.16900 \\
\hline Blantyre & Masanjala Lilangwe & 77 & 5 & 6.5 & I5.54490 & 35.02184 \\
\hline Chiradzulu & Mbalame & 81 & 6 & 7.4 & 15.70000 & 35.10000 \\
\hline Chitipa & Chisenga & 85 & 0 & 0 & 9.97500 & 33.38977 \\
\hline Chitipa & Siyombwe & 77 & 0 & 0 & 9.68441 & 33.24764 \\
\hline Dedza & Kamenyagwaza & 64 & 5 & 7.8 & 14.40750 & 34.98750 \\
\hline Dowa & Chimangamsasa & 72 & 4 & 5.6 & 13.70964 & 33.99795 \\
\hline Kasungu & Kadyaka & 65 & 0 & 0 & 13.07633 & 33.48360 \\
\hline Kasungu & Kaluluma & 105 & 3 & 2.9 & 12.58077 & 33.51870 \\
\hline Lilongwe & Mwenda I T/A Chadza & 84 & 6 & 7.1 & $14 . \mid 4074$ & 33.78825 \\
\hline Machinga & Phuteya & 70 & 3 & 4.3 & 15.19000 & 35.09887 \\
\hline Mangochi & Chilawe & 92 & 9 & 9.8 & 13.80000 & 35.10300 \\
\hline Mangochi & Chiponde & 90 & 12 & 13.3 & 14.38300 & 35.10000 \\
\hline Mangochi & Mtuwa & 82 & 21 & 25.6 & 14.68400 & 35.55100 \\
\hline Mchinji & Chalaswa & 98 & 4 & 4.1 & 14.11689 & 33.32919 \\
\hline Mchinji & Mzenga & 99 & 18 & 18.2 & 13.60427 & 32.73460 \\
\hline Mulanje & Gawani & 78 & 6 & 7.7 & 15.98100 & 35.78300 \\
\hline Mulanje & Mbewa & 69 & 13 & 18.8 & I5.99970 & $35.486 \mathrm{II}$ \\
\hline Mwanza & Chapita A & 64 & 3 & 4.7 & 15.63022 & 34.59139 \\
\hline Mzimba & Milingo-Jere & 101 & 0 & 0 & 12.20374 & 33.33340 \\
\hline Mzimba & Kambombo & 102 & 2 & 1.9 & II.1755I & 33.52649 \\
\hline Nkhata-Bay & Kalumpha & 104 & 7 & 6.7 & 12.08733 & 34.05695 \\
\hline Nkhata-Bay & Mizimu & 103 & 8 & 7.8 & II.55820 & 34.18150 \\
\hline Nkhotakota & Mowe & 122 & 11 & 9 & 12.55496 & 34.13366 \\
\hline Nkhotakota & Tandwe & 81 & 3 & 3.7 & |3.0298| & 34.26246 \\
\hline Ntcheu & Gwaza & 92 & 26 & 28.3 & 14.52800 & 34.68000 \\
\hline Ntcheu & Nkonde-I & 66 & 6 & 9.1 & |4.98570 & 34.82825 \\
\hline Ntchisi & Kalulu & 99 & 3 & 3 & 13.33129 & 33.74804 \\
\hline Phalombe & Maguda & 78 & 19 & 24.4 & 15.51774 & 35.78996 \\
\hline Rumphi & Bongololo & 72 & 1 & 1.4 & 10.81276 & 33.52233 \\
\hline Rumphi & Mhango & 82 & 8 & 9.8 & 10.81000 & 33.52379 \\
\hline Salima & Chipoka-Nkwizi & 73 & 16 & 21.9 & 14.03676 & 34.50614 \\
\hline Salima & Kasonda & 78 & 13 & 16.7 & 13.59828 & 34.29268 \\
\hline Thyolo & Nkaombe & 95 & 6 & 6.3 & $|5.9927|$ & 35.04998 \\
\hline Zomba & Kapenda & 57 & 2 & 3.5 & 15.35885 & 35.40305 \\
\hline
\end{tabular}

onion farming. Whether this setting is conducive for supporting extensive mosquito breeding and thus driving $W$. bancrofti infection as has been observed in Northern Malawi and Ghana will need further investigation [14]. Ideally this should be coupled with human night blood examination for microfilariae.

It is also interesting to note that some villages from districts (Rumphi, Nkhata-Bay and Nkhotakota) along the lake shore had prevalence of less than $10 \%$. A possible explanation could be due to the fact that these districts are mountainous and thus well drained consequently limiting potential mosquito breeding sites.

The relatively high prevalence found in Salima, Ntcheu (Bwanje Valley), Balaka, Mangochi and Phalombe was unexpected. However there have been isolated unpublished reports of cases with chronic manifestation of LF (hydrocele and elephantiasis) in these areas. It is worth noting that the ecological conditions in these districts are ideal for supporting large potential LF vector populations. Incorporating data from 2000 surveys clearly shows that the priority areas for LF control activities in Malawi will be the lakeshore districts, Phalombe plain and the Lower Shire Valley.

The decline in LF prevalence with increasing altitude has also been reported from other settings in Africa [15]. This is believed to be due to the influence of altitude on temperature which is known to be critical for survival of the vector and development of the parasite within the vector [16].

These findings have important implications for initiating the "Malawi LF Elimination Programme". First, following WHO's recommendation that all implementation units 

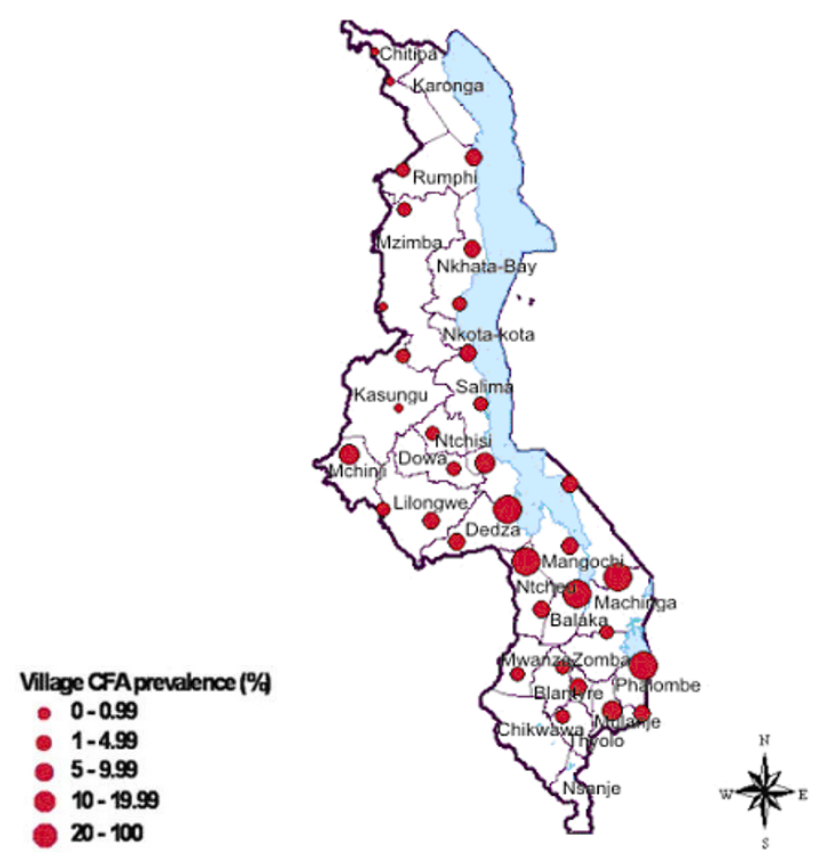

with a prevalence on ICT of over $1 \%$ be considered endemic and thus treated, the Malawi programme would involve 27 districts with a target population of over ten million. The population affected is far greater than ever envisaged. Secondly, both the northern (Karonga) and Southern foci (the Lower Shire Valley) share international borders which are largely porous. This calls for innovative approaches in carrying out control activities as they have to be synchronised with those in neighbouring countries. Thirdly, in some districts (Phalombe, Mulanje, Thyolo, Chikwawa and Mwanza) where LF is co-endemic with onchocercisasis the two programmes will need to be merged. Fourthly, the LF programme will need to establish links with other programmes that are delivering community based interventions such as the ministry of education's deworming and feeding programme and the expanded bed net distribution under the malaria control programme.

Figure 3

Map of Malawi showing the prevalence levels recorded in the 2003 survey.

Table 2: ICT antigen prevalence data from surveys conducted in 2000

\begin{tabular}{|c|c|c|c|c|c|c|}
\hline District & Village & Number tested & Number positive & Prevalence & Latitude & Longitude \\
\hline Karonga & Mwenitete & 42 & 20 & 47.6 & 9.71257 & 33.92973 \\
\hline Karonga & Mwakyusa & 91 & 44 & 48.7 & 9.69795 & 33.89313 \\
\hline Karonga & Mwenepela & 102 & 59 & 57.8 & 9.67193 & 33.8252 \\
\hline Karonga & Kashata & 50 & 22 & 44 & 9.73315 & 33.88652 \\
\hline Karonga & Mwamsaku & 50 & 22 & 44 & 9.8092 & 33.86483 \\
\hline Karonga & Mwambetania & 50 & 29 & 58 & 9.86747 & 33.86892 \\
\hline Karonga & Kafikisila & 51 & 23 & 45.1 & 9.91213 & 33.93105 \\
\hline Karonga & Mwenitete-mpata & 50 & 24 & 48 & 9.94957 & 33.82237 \\
\hline Karonga & Ngosi & 50 & 15 & 30 & 10.01228 & 33.94907 \\
\hline Karonga & Mwakabanga & 50 & 15 & 30 & 10.14422 & 34.01782 \\
\hline Karonga & Kanyuka & 51 & 14 & 27.5 & 10.30768 & 34.12692 \\
\hline Karonga & Bonje & 50 & 28 & 56 & 10.49027 & 34.17098 \\
\hline Nsanje & Chazuka & 148 & 60 & 40.5 & $|6.8426|$ & 35.25259 \\
\hline Nsanje & Nchachal 8 & 148 & 86 & 58.1 & 16.63617 & 35.17126 \\
\hline Nsanje & Gamba & 84 & 56 & 66.7 & $|6.581|$ & 35.14076 \\
\hline Chikwawa & Nchingula & 128 & 76 & 59.4 & 15.99828 & 34.48297 \\
\hline Chikwawa & Zilipaine & 129 & 96 & 74.4 & 16.07998 & 34.88262 \\
\hline Chikwawa & Mbande & 108 & 76 & 70.4 & 16.16167 & 34.79332 \\
\hline Chikwawa & Pende & 116 & 79 & 68.1 & 16.04362 & 34.72428 \\
\hline Chikwawa & Belo & 196 & 155 & 79.1 & 16.02093 & 34.8162 \\
\hline Chikwawa & Mfunde & 87 & 29 & 33.3 & 16.19929 & 35.01652 \\
\hline Chikwawa & Kasokeza & 60 & 34 & 56.7 & 16.11213 & 34.92532 \\
\hline Chikwawa & Khumbulani & 59 & 9 & 15.3 & 15.99232 & 34.8791 \\
\hline Chikwawa & Muyaya & 78 & 21 & 26.9 & 16.04667 & 34.90783 \\
\hline
\end{tabular}




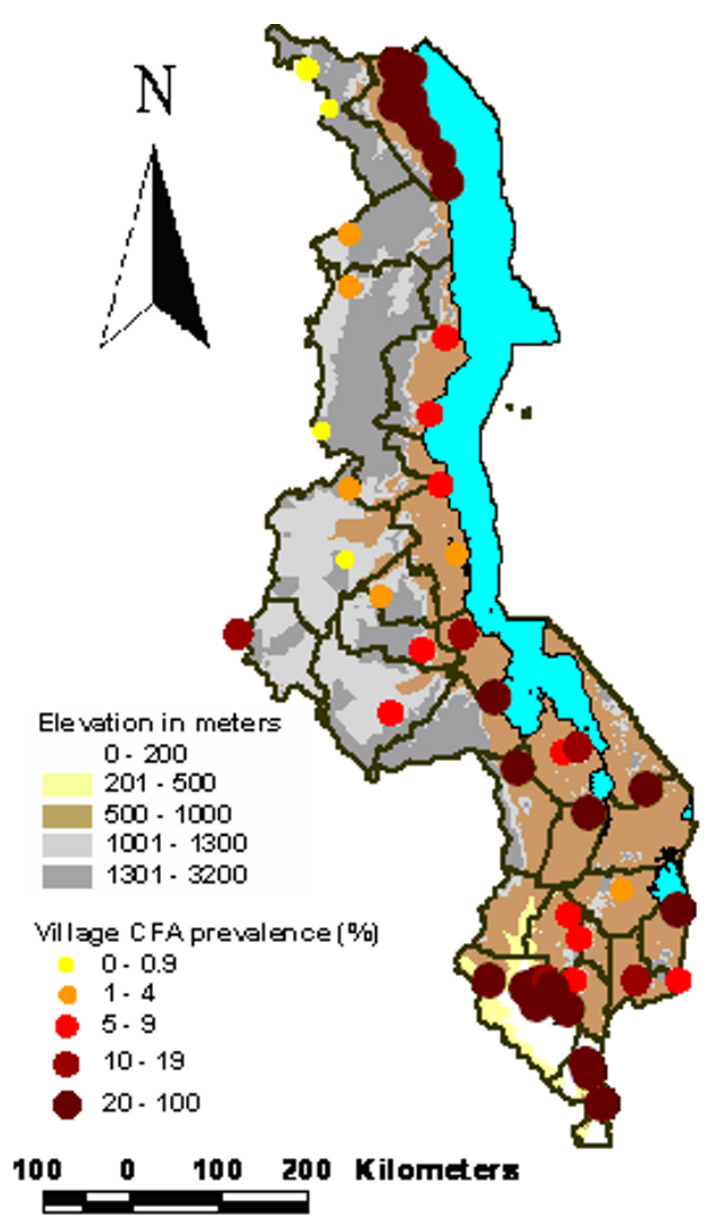

Figure 4

Map of Malawi showing prevalence of all sampled villages (except 2 villages in Nsanje District) in relation to altitude (metres).

\section{Acknowledgements}

This survey received financial support from the Gates Foundation through the WHO's AFRO office (Sticker No. AF/02/P227728) and the Lymphatic Filariasis Support Centre (supported by the UK's Department of International Development) at the Liverpool School of Tropical Medicine. Technical and administrative support was provided by the Malawi Ministry of Health through the National Onchocerciasis Task Force Office and the Malawi College of Medicine. BN received financial support from a WHO/ TDR fellowship.

\section{References}

I. Michael E, Bundy DA, Grenfell BT: Re-assessing the global prevalence and distribution of lymphatic filariasis. Parasitology 1996, I I 2(Pt 4):409-428.

2. Ravindran B: Aping Jane Goodall: insights into human lymphatic filariasis. Trends Parasitol 2003, 19:105-109.

3. Ottesen EA: The global programme to eliminate lymphatic filariasis. Trop Med Int Health 2000, 5:59I-594.

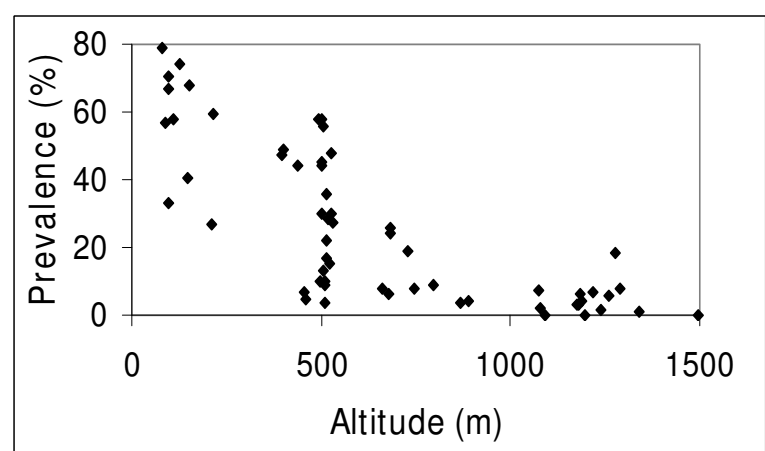

(a)

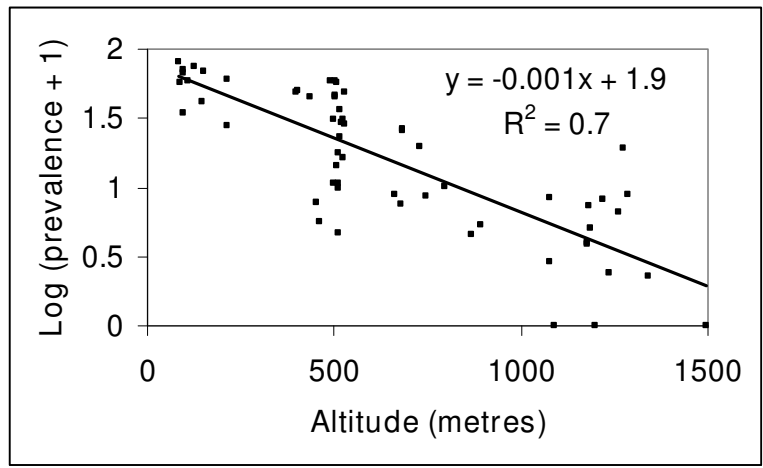

(b)

Figure 5

Prevalence plotted against altitude (metres) (a) and log transformed (prevalence + I) plotted against altitude (metres) (b).

4. Molyneux DH, Taylor MJ: Current status and future prospects of the Global Lymphatic Filariasis Programme. Curr Opin Infect Dis 200I, I 4:155-159.

5. Oram RH: Filariasis on the North Nyasa lake shore. Cent Afr J Med 1958, 4:99-103.

6. Hawking F: The distribution of human filariasis throughout the world. Part III. Africa. Trop Dis Bull 1977, 74:649-679.

7. Oram RH: Filariasis on the North Nyasa lake shore (II). Cent Afr J Med 1960, 6: I44-I45.

8. Nielsen NO, Makaula $P$, Nyakuipa D, Bloch $P$, Nyasulu $Y$, Simonsen PE: Lymphatic filariasis in Lower Shire, southern Malawi. Trans R Soc Trop Med Hyg 2002, 96:133-138.

9. Ngwira BM, Jabu CH, Kanyongoloka H, Mponda M, Crampin AC, Branson K, Alexander ND, Fine PE: Lymphatic filariasis in the Karonga district of northern Malawi: a prevalence survey. Ann Trop Med Parasitol 2002, 96: 137-I 44.

10. Gyapong JO, Remme JH: The use of grid sampling methodology for rapid assessment of the distribution of bancroftian filariasis. Trans R Soc Trop Med Hyg 200I, 95:68I-686.

II. Anon: Update on rapid assessment of bancroftian filariasis. TDR News 1999, 60:.

12. Weil G], Lammie PJ, Weiss N: The ICT Filariasis Test: A rapidformat antigen test for diagnosis of bancroftian filariasis. Parasitol Today 1997, 1 3:401-404.

13. Wamae CN, Gatika SM, Roberts JM, Lammie PJ: Wuchereria bancrofti in Kwale District, Coastal Kenya: patterns of focal distribution of infection, clinical manifestations and anti-filarial IgG responsiveness. Parasitology 1998, I I 6(Pt 2): 173-182.

14. Hunter JM: Elephantiasis: a disease of development in north east Ghana. Soc Sci Med 1992, 35:627-645. discussion 645-629 
15. Onapa AW, Simonsen PE, Baehr I, Pedersen EM: Rapid assessment of the geographical distribution of lymphatic filariasis in Uganda, by screening of schoolchildren for circulating filarial antigens. Ann Trop Med Parasitol 2005, 99: I4I-I53.

16. Lardeux F, Cheffort J: Ambient temperature effects on the extrinsic incubation period of Wuchereria bancrofti in Aedes polynesiensis: implications for filariasis transmission dynamics and distribution in French Polynesia. Med Vet Entomol 200I, I5:167-176.

Publish with Biomed Central and every scientist can read your work free of charge

"BioMed Central will be the most significant development for disseminating the results of biomedical research in our lifetime. " Sir Paul Nurse, Cancer Research UK

Your research papers will be:

- available free of charge to the entire biomedical community

- peer reviewed and published immediately upon acceptance

- cited in PubMed and archived on PubMed Central

- yours - you keep the copyright

Submit your manuscript here:

http://www.biomedcentral.com/info/publishing_adv.asp 